\title{
The critical point, and the phenomenon of the disappearance of the meniscus when a liquid is heated under constant volume
}

\section{G. Zambiasi}

To cite this article: G. Zambiasi (1893) The critical point, and the phenomenon of the disappearance of the meniscus when a liquid is heated under constant volume, Philosophical Magazine Series 5, 36:219, 231-232, DOI: 10.1080/14786449308620471

To link to this article: http://dx.doi.org/10.1080/14786449308620471

曲 Published online: 08 May 2009.

Submit your article to this journal $[\pi$

山 Article views: 7

Q View related articles $\sqsubset$ 
$193^{\circ}$. The two columns of mercury presented a greater or less difference according to the initial difference. The equalization of the mercury-levels took place at $196^{\circ}$. The formula expressing the equilibrum of the two parts of the tube shows that the course of the difference of level corresponds very appreciably to that of the difference between the density of the liquid and that of the vapour.

The phenomenon of Cagniard de Latour was observed in seven tubes, in which the volumes of the liquid and the vapour were, at the temperature of $18^{\circ} \cdot 6$, respectively in the following ratios:-

$$
\begin{array}{ccccccc}
4 & 2 & 1 & 6 & \frac{4}{5} & \frac{4}{10} & \frac{7}{5} .
\end{array}
$$

From the results obtained the author concludes that, in order that the meniscus can be observed in the tube, the ratio $\frac{v}{v_{1}}$ of the volume of the liquid to the volume of the vapour at the ordinary temperature must not be below a lower limit comprised between

$$
\frac{1}{4} \text { and } \frac{2}{5}
$$

nor above a higher limit comprised between

$$
\frac{9}{10} \text { and } \frac{7}{5} \text {. }
$$

Comparative experiments on several tubes heated in the same bath have shown that the temperature at which the meniscus disappears is not constant for the same body, but depends on the quantity of this body compared in a given volume. In the same tube the reappearance was constantly observed at the same temperature as the disappearance.-Journal de Physique, June 1893.

THE CRITICAL POINT, AND THE PHENOMENON OF THE DISAP-

PEARANCE OF THE MENISCUS WHEN A LIQUID IS HEATED UNDER CONSTANT VOLUMW. BY G. ZAMBIASI.

The fact established by the author in the above Note, that the temperature $t_{c}$ at which the meniscus disappears is not constant, but rises when the ratio of the initial volume of the liquid to the volume of the vapour disappears, might have been foreseen from Jamin's experiments, in which the disappearance of the meniscus was obtained by a compression at constant temperature. M. Amagat has demonstrated the same fact in a still more accurate manner in producing, by a slow increase of pressure of carbonic acid, the disappearance at $30^{\circ} .50$, when heat alone produces disappearance at $31^{\circ} .55$. If the temperature $t_{c}$ was singular, it would be independent of the compression.

It does not increase the tension, which is a maximum; but by condensing the vapour it increases the volume and the mass of the liquid, so that the ratio of the volumes increases. 
The densities $d$ and $d^{\prime}$ and the volumes $v$ and $v^{\prime}$ of the liquid and the vapour, when a mass $m$ of a body in a closed ressel at constant volume is heated, should at all temperatures satisfy the equations

We have then

$$
\begin{aligned}
v d+v^{\prime} d^{\prime} & =m, \\
v+v^{\prime} & =\nabla .
\end{aligned}
$$

$$
\frac{v}{v^{\prime}}=\frac{m-V d^{\prime}}{\bar{V} d-m} .
$$

Discussing this expression, the author shows that the meniscus disappears at the critical point if $\nabla$ is the volume of the mass worked with.

If a mass of a body is subjected to a gradual heating in a volume near its critical one, though a little lower, it will successively reach a condition in which the meniscus disappears; a condition in which its pressure will be equal to the critical pressure, when its temperature is equal to the critical temperature; in fine, to a distinctly gaseous state. From the moment at which the meniscus disappears that pressure is no longer independent of the mass. Between this moment and that at which it reaches the critical temperature the body is in a state which corresponds neither to a mass of gas, nor to a mass of vapour and of gas in juxtaposition. It may be regarded as a mixture or as a solution of the two kinds of matter.

If the constant volume in which the mass in question is enclosed is equal to its critical volume $V$, the disappearance of the meniscus, the reestablishment of the level of the mercury in the $O$ tubes, the critical pressure, and the critical temperature should be simultaneously realized.

In order to be certain that a body has been brought to the critical state, we must be certain that it offers simultaneously two elements characteristic of this state. The disappearance of the meniscus, and the reestablishment of the level in the capillary tubes taken separately are not sufficient indieations, for they may take place outside the critical condition. On the contrary, equality of the densities or of the specific volumes of the liquid and of the vapour will be a sufficient datum, since it is equivalent to two critical elements.

In conclusion, in order that the method of heating a body at constant volume shall offer certain indications of the critical conditions, the author proposes to perfeet it by providing the $\mathrm{O}$ tube with a regulator of rolume. By suitably modifying the volume by trials the disappearance of the meniscus and the reestablishment of the level of mercury might be obtained at the same instant. The space occupied by the body will then be the critical volume; on the other hand, the temperature and the pressure will then be also those of the critical point.-Journal de Physique, June 1893. 